\title{
The effect of oxygen plasma treatment on the hydrophobicity of polyaniline surface
}

\author{
Nugrahani Primary Putri \\ Physics Department \\ Universitas Negeri Surabaya \\ Surabaya, Indonesia \\ nugrahaniprimary@unesa.ac.id
}

\author{
Rani Putri Lavinia, D.J. Djoko H. Santjojo, Masruroh, \\ Setyawan Purnomo Sakti \\ Physics Department \\ Brawijaya University \\ Malang, Indonesia
}

\begin{abstract}
Polyaniline is one of the conductive polymers that can be funcionalized as a sensitive layer on quartz crystal microbalance (QCM). The sensitivity of polyaniline can be enhanced via dedicated its morphology. The plasma oxygen treatment is used to modify the surface of polyaniline coating. The purpose of this study was to determine the effect of power variations on plasma treatment on roughness and the surface hydrophobicity properties of polyaniline. Plasma oxygen is generated with a power variation of $24 \mathrm{~W}, 30 \mathrm{~W}$ and $42 \mathrm{~W}$, for 60 second and a flow rate of $50 \mathrm{ml} / \mathrm{sec}$. The oxygen plasma treatment affects the polyaniline surface roughness and hydrophobicity. As the power increases, the roughness of polyaniline was decreases. Simultaneously the polyaniline surface turns into hydrophilic. From FTIR and OES characterization it is observed that there has been an interaction between OI oxygen radical species with polyaniline functional groups on the surface of the coating. This interaction causes the polyaniline surface to be flattened and increase its hydrophilicity.
\end{abstract}

Keywords-oxygen plasma treatment; polyaniline; surface modification; hydrophobicity

\section{INTRODUCTION}

Plasma surface modification is an effective and economical surface treatment technique for many materials including polymer. When polymer is exposed to plasma and if the plasma density and treatment time is proper, much functionality will be created near the surface and cross-linked polymer chains can be formed. Generally, polymers are hydrophobic, and conversion of these polymers from being hydrophobic to hydrophilic usually improves the adhesion strength, biocompatibility, and other pertinent properties. Formation of oxygen functionalities by ion implantation is one of the most useful and effective process of surface modification [1].

Polyaniline (PANi) has much attention as a popular kind of conducting polymer with various exceptional properties, such as environmental stability, ease of synthesis, and low cost of raw materials. PANi is one of conductive polymer that already applied as sensor, anti-corrosive coating, and even supercapacitors [2]. Until now, various kinds of PANi and their composite sensors based on the electrochemical property have been fabricated to detect volatile organic compounds (VOC's). PANi shows diverse chemical structures and different response mechanism upon exposure to different gases [3-4]. There are five different PANi-based sensor classes, based upon different operating modes, which are: (i) conductometric mode (changes in electrical conductivity), (ii) potentiometric mode (changes in chemical potential without current flow), (iii) amperometric mode, (iv) colorimetric mode (changes in optical adsorption) and (v) gravimetric mode (change in the polymer weight, as a result of analyte-PANi interaction) [5]. In gravimetric mode, it has been reported that PANi can be deposited on Quartz Crystal Microbalance (QCM) as sensitive layer and has good sensitivity on alcohol vapors [6], ether and chloroform [7], para-xylene [8], free radical [9] and hydrochloric acid [10]. Gas sensing properties of PANi can be enhanced via surface modification using plasma treatment, especially oxygen plasma. It was observed that the oxygen plasma treatment markedly improved the ability of the PANi-based sensor to detect hydrogen. The responds times and the sensor recovery considerably shortened after the plasma treatment [11].

Quartz Crystal Microbalance (QCM) is a device that has a working principle based on changes in the oscillation frequency which is proportional to changes in the deposited mass. The sensitivity and specificity of QCM-based immunosensors is dependent on the immobilization of recognition layer. In the development of QCM sensor, hydrophobicity affects biomolecule immobilization on the sensor surface. Plasma power effects on the surface of QCM sensor have been studied. The applied power had an effect on etching rate and on the anisotropy of the etched profile [12]. The purpose of this research is to study the effect of plasma power on the hydrophobicity of polyaniline as sensitive layer on the QCM sensor.

\section{EXPERIMENTAL PROCEDURES}

\section{A. Polymerization of polyaniline (PANi)}

Polyaniline was obtained by the chemical oxidative polymerization process. The oxidative polymerization reaction of aniline occurred by adding oxidant monomers like ammonium persulfate (APS) to aniline dissolved in an acid solution. For the aniline aqueous solution, $1.82 \mathrm{ml}$ aniline was dissolved in $50 \mathrm{ml}$ of $1 \mathrm{M} \mathrm{HCl}$ doping acid. For the oxidant solution, APS (5.71 gr) was dissolved in $50 \mathrm{ml}$ of $1 \mathrm{M} \mathrm{HCl}$ 
doping acid. The oxidant solution was quickly poured into the aniline solution at room temperature followed by immediate magnetic stirring. The stirring was stopped after $2 \mathrm{~h}$, and the solution left undisturbed for $24 \mathrm{~h}$. The green precipitates were filtrate with filter paper and wash with distilled water.

\section{B. PANi deposition on QCM surface}

0.26 gr PANi was dissolved in $10 \mathrm{ml}$ NMP then the solution was stirred using a magnetic stirrer for 2 hours and homogenized using ultrasonic cleaner for 2 hours. PANi solution that has been homogeneous is then deposited on the QCM surface by spin coating method with a speed of 4000 $\mathrm{rpm}$ for 60 seconds. QCM is then heated at $100^{\circ} \mathrm{C}$ for 5 minutes so that the PANi layer is attached to the QCM surface.

\section{Oxygen plasma treatment}

The treatment of oxygen plasma on the QCM substrate uses Plasma $2 \mathrm{MHz} \mathrm{RF}$ device, with a power variation of $24 \mathrm{~W}, 30 \mathrm{~W}$ and $42 \mathrm{~W}$, for 60 second and a flow rate of 50 $\mathrm{ml} / \mathrm{sec}$.

\section{Characterization}

Both treated and untreated surface were characterized by Fourier Transform Infrared spectroscopy using Shimadzu FTIR spectrometer in $4000-500 \mathrm{~cm}^{-1}$. Contact angle of the samples was measured by the sessile drop method, using the optical goniometer by employing distilled water as liquid as reported before [13]. Surface roughness before and after plasma treatment is determined by TMS-1200 Polytech. The optical emission spectroscopy (OES) was used to determine the species in plasma during process.

\section{RESULT AND ANALYSIS}

\section{A. IR-Spectra study}

IR spectrum of PANi layer which is deposited above the QCM surface before plasma treatment can be seen in Figure 1. When compared to the IR spectrum of PANi-powder, there are several missing peaks, namely in the wave number range between $750-1250 \mathrm{~cm}^{-1}$. The PANi's peaks that were lost are identification for C-C stretch bonds (1124.18 $\left.\mathrm{cm}^{-1}\right), \mathrm{C}-\mathrm{N}$ stretch $\left(1224.55 \mathrm{~cm}^{-1}\right)$ and $\mathrm{C}-\mathrm{H}$ bending $\left(1298 \mathrm{~cm}^{-1}\right)$ [14]. No detection of PANi's peaks in this range can be caused by infrared waves in the range absorbed by quartz crystal because it is not associated with any change in the electric moment [15]. PANi's peaks detected were out-of-ring ring bending $\left(700.11 \mathrm{~cm}^{-1}\right)$; benzenoid ring stretching $\left(1490.87 \mathrm{~cm}^{-1}\right)$ [16] and quinone oximes $\left(2700-3540 \mathrm{~cm}^{-1}\right)$ [17], while other peaks belong to quartz crystal microbalance (QCM) as substrate [15].

The effect of plasma treatment to the PANi's chemical bonds which deposited on the QCM surface can be seen in Figure 2. The quinone oximes peaks $\left(2882.45 \mathrm{~cm}^{-1} ; 2952.81\right.$ $\mathrm{cm}^{-1}$; and $3442.70 \mathrm{~cm}^{-1}$ ) which namely the bond between PANi's quinone group with oxygen and hydrogen, are missing due to the binding of $\mathrm{OH}$ groups with oxygen atoms forming $\mathrm{H}_{2} \mathrm{O}$ molecules. The effect of oxygen plasma treatment varying power cannot be detected on the bond that occurs on the PANi surface by FTIR spectra. The reason why no significant changes can be observed, could be attributed to the fact that surface modification by oxygen plasma only involves very superficial changes on the treated surface, in order of nanometers, while the analysis by FTIR technique is from 1-5 $\mu \mathrm{m}$ in depth [18].

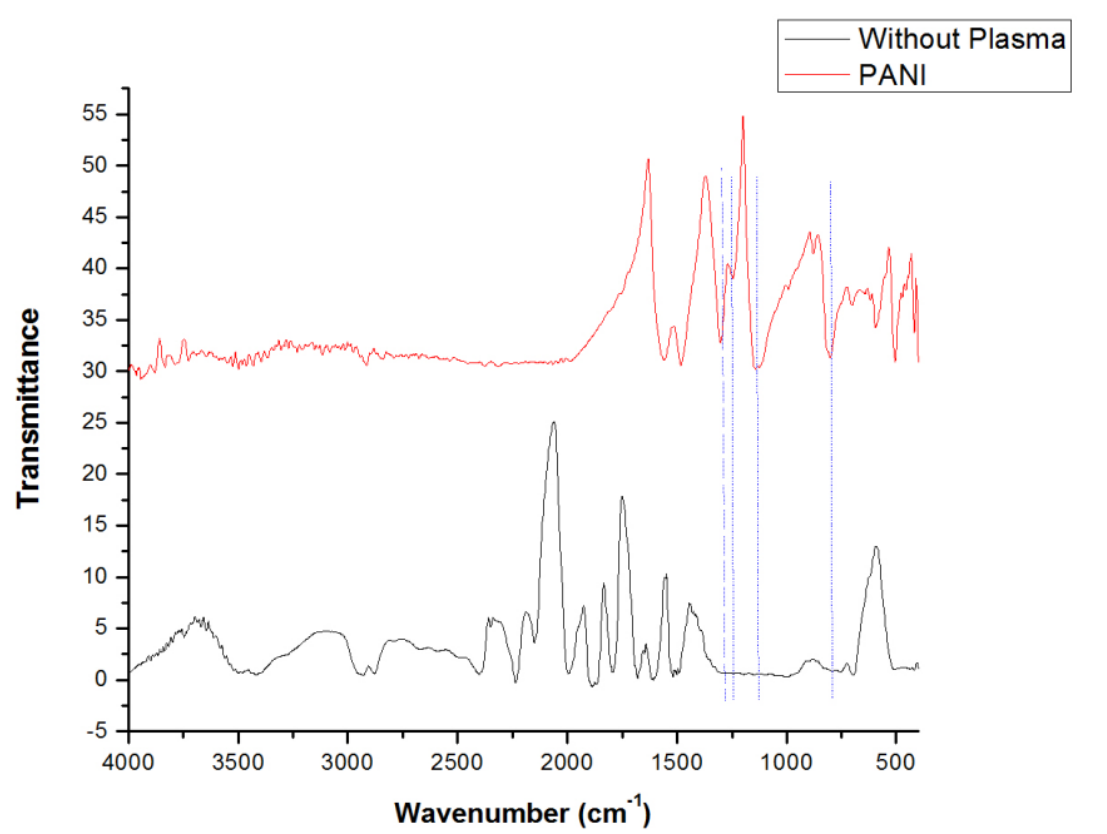

Figure 1. IR-spectra for PANi powder and PANi layer deposited in QCM surface without plasma treatment 


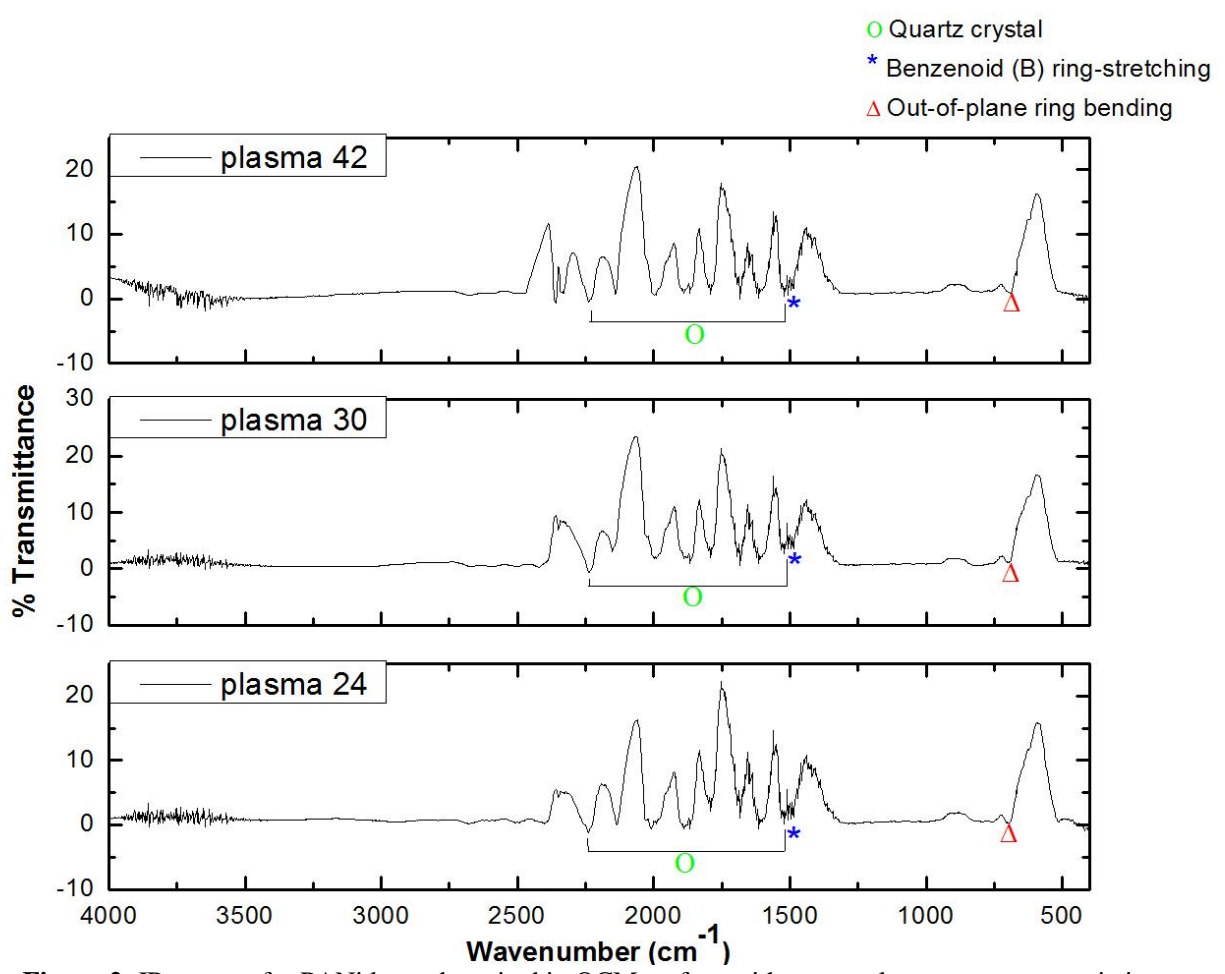

Figure 2. IR-spectra for PANi layer deposited in QCM surface with power plasma treatment variation

\section{B. OES Spectra}

Optical emission spectroscopy (OES) is an in situ and widespread diagnostic technique with a simple set-up for easy identification of the active species in the surface modification. Figure 4 shows the overall emission spectra during modification process at different plasma power. The emission spectra have been acquired in the wavelength range of 200$1100 \mathrm{~nm}$ at different treatment powers, which are $24 \mathrm{~W}, 30 \mathrm{~W}$ and $42 \mathrm{~W}$. In the process of plasma oxygen with a power of $24 \mathrm{~W}$, instability occurs. This can be seen from the OES spectrum, there is no OI peak in this spectrum. On the otherhand, there is only a OIII spectral at wavelength around $393 \mathrm{~nm}$. The OES spectra at $30 \mathrm{~W}$ oxygen plasma treatment, its dominated by two OI oxygen active species lines at about 777 and $842 \mathrm{~nm}$ which corespond to atomic transition $\mathrm{O}\left(3 \mathrm{p}^{5} \mathrm{P}\right.$ to $\left.3 s^{5} \mathrm{~S}\right)$ and $\mathrm{O}\left(3 \mathrm{p}^{3} \mathrm{P}\right.$ to $\left.3 \mathrm{~s}^{3} \mathrm{~S}\right)$, respectively [19]. The OIII line has higher intensity compared to $24 \mathrm{~W}$ and 42 spectral. OI and OIII are radical oxygen species that are easily bound to other atoms or molecules. There are several $\mathrm{CO}$ bonds that indicate the chemical interaction between plasma oxygen and PANi (see Figure 3). The appearance of $\mathrm{CO}$ bands indicates the strong oxidation of PANi [20]. In the $42 \mathrm{~W}$ spectrum there is an additional peak, OII at a wavelength of $653 \mathrm{~nm}$, which is a neutral oxygen species. The existence of OII will reduce the degree of ionization of plasma oxygen so that it can reduce the bonds that occur between plasma oxygen and PANi.

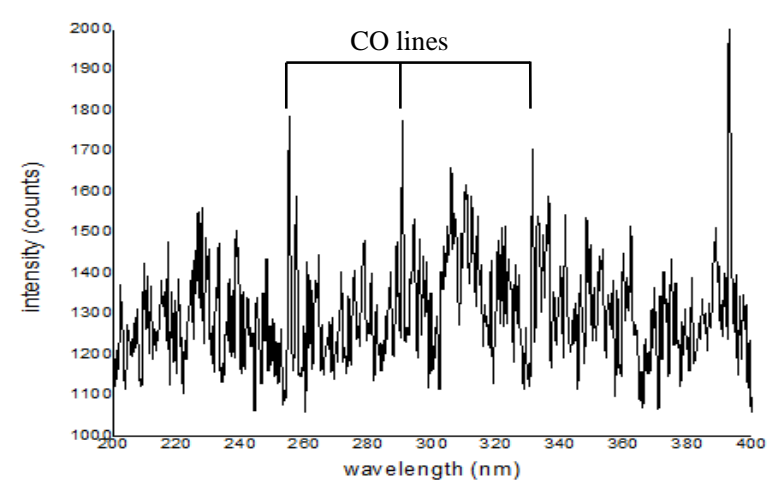

Figure 3. OES-spectra at 30W 


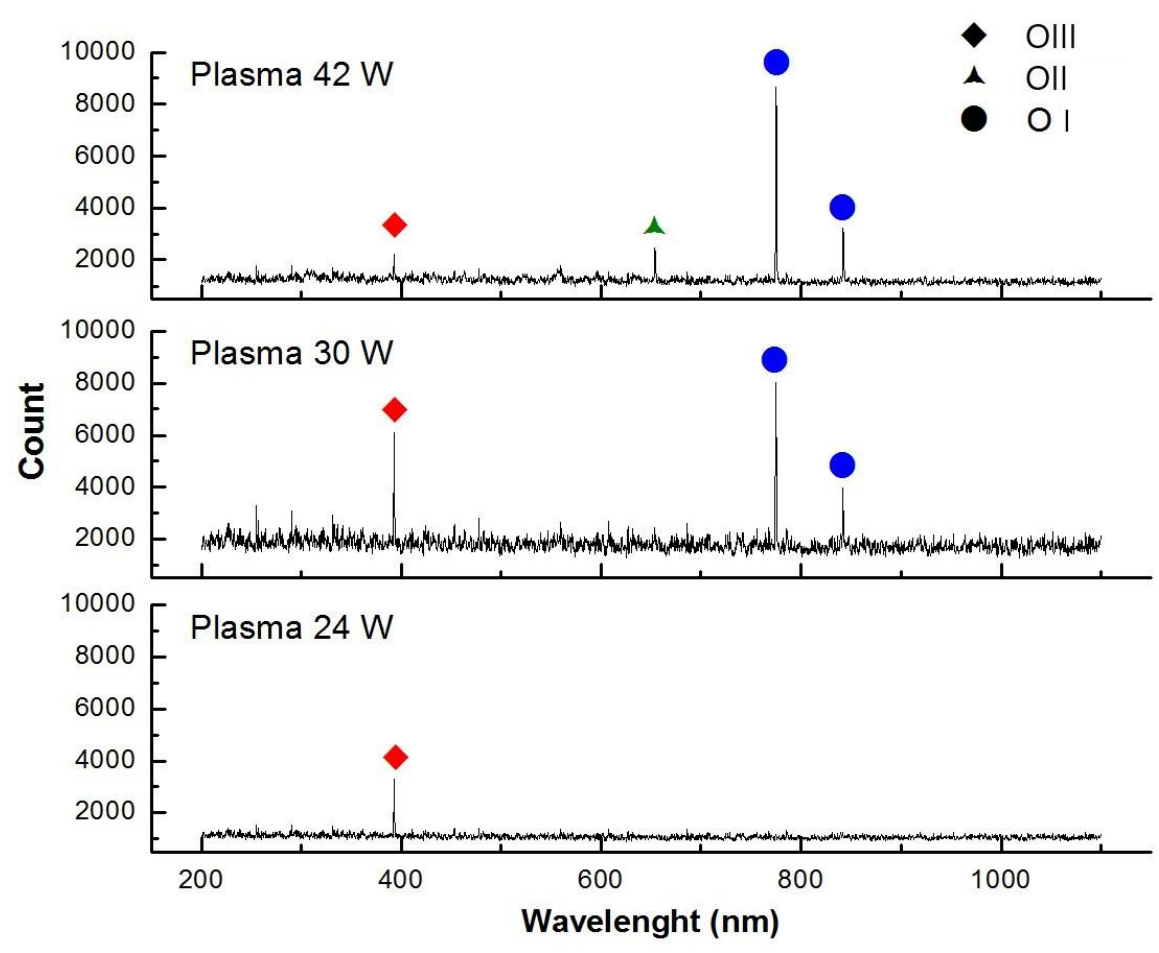

Figure 4. OES spectra of PANi with variation of power plasma treatment

\section{Surface roughness and contact angle measurement}

Oxygen plasma exposure on the PANi surface affects the changes of PANi surface roughness. After being treated with plasma oxygen, the surface becomes smoother than before plasma treatment. High-energy collisions caused by an increase in plasma power, causing the enhancement of ionization and recombination processes (see Figure 5).

From Table I, it can be seen that the increase in plasma power is not linear compared to increase in surface roughness. This nonlinearity can be caused due to differences in plasma species that produced. In plasma oxygen treatment process with $30 \mathrm{~W}$ power, the resulting plasma species (OI and OIII) are very reactive in oxidizing polyaniline, thus affecting the surface roughness of the polyaniline layer better than OII .

The hydrophobicity of a surface is related to its surface energy, the greater the surface energy, the surface became more hydrophilic. On a hydrophilic surface, the adhesion force that occurs between the liquid and the substrate surface is larger, so that the water droplets will spread evenly on the surface of the substrate. Not only related to surface energy, the wettability of the surface also depends on its morphology, the hydrophilic surface tends had to be smoother. In this study, the magnitude of the contact angle on the surface after plasma treatment was smaller than before the plasma treatment (see Figure 6).
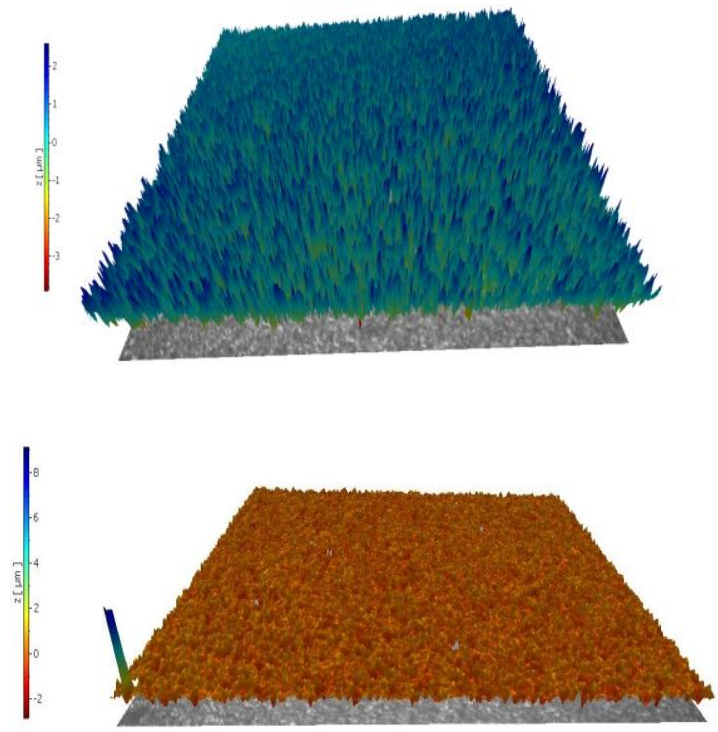

Figure 5. Surface roughness of PANi surface before and after oxygen plasma treatment 
TABLE I. COMPARISON OF THE DIFFERENCE IN SURFACE ROUGHNESS BEFORE AND AFTER PLASMA TREATMENT

\begin{tabular}{|c|c|c|c|}
\hline \multirow{2}{*}{$\begin{array}{c}\text { Power } \\
\text { (watt) }\end{array}$} & \multicolumn{3}{|c|}{ Surface Roughness (nm) } \\
\cline { 2 - 4 } & Before treatment & After treatment & A (nm) \\
\hline 24 & 277.44 & 243.91 & 33.52 \\
\hline 30 & 347.39 & 260.79 & 86.59 \\
\hline 42 & 361.91 & 319.27 & 42.64 \\
\hline
\end{tabular}

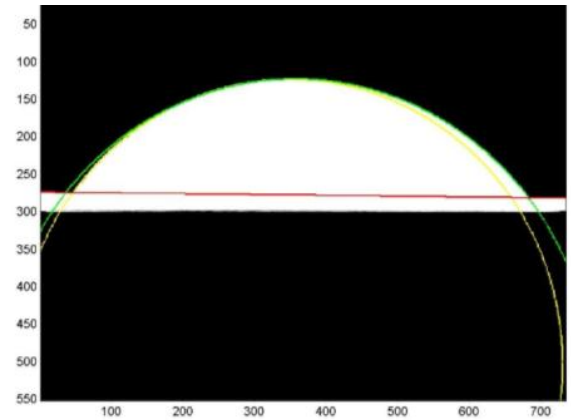

(a)

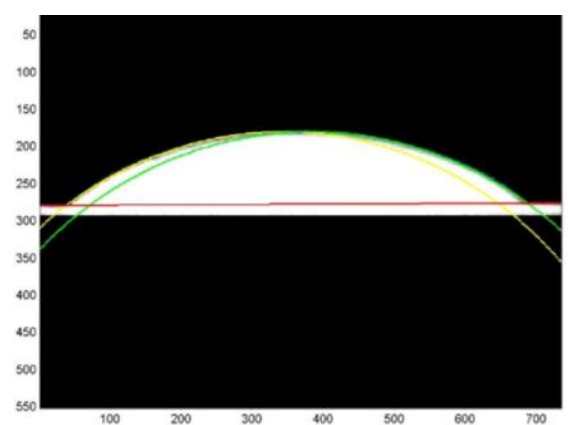

(b)

Figure 6. Contact angle measurement before and after plasma treatment at $30 \mathrm{~W}$

The reduction in contact angle in water when the power plasma was increased can be seen at Table II. The most significant decrease in contact angle occurs on the surface after plasma treatment with a power of $30 \mathrm{~W}$. This is consistent with the measurement of surface roughness, where the greatest surface roughness occurs after plasma treatment with a power of $30 \mathrm{~W}$. Ion generated at high power in the plasma are accelerated across the plasma sheath surrounding PANi's surface and then interact with the surface and creating dangling bonds, which improve the adhesive properties. When compared to previous research [21], the improvement of PANi hydrophilicity of PANi is more due to the interaction of its surface with radical OI and OIII atoms.
TABLE II. COMPARISON OF THE DIFFERENCE IN CONTACT ANGLE BEFORE AND AFTER PLASMA TREATMENT

\begin{tabular}{|c|c|c|c|}
\hline \multirow{2}{*}{$\begin{array}{c}\text { Power } \\
\text { (watt) }\end{array}$} & Before treatment & After treatment & $\boldsymbol{\Delta}^{\circ}$ ) \\
\cline { 2 - 4 } & 76.764 & 66.657 & 10.107 \\
\hline 30 & 55.312 & 31.027 & 24.285 \\
\hline 42 & 55.811 & 40.735 & 15.076 \\
\hline
\end{tabular}

\section{CONCLUSION}

From this research can be concluded that the interaction between the substrate and the ions produce surface activation with formation of dangling bonds which react with the oxygen radicals present in plasma phase, as resulted from OES analysis, and cause a surface functionalization. Contact angle measurement confirms the enhancement of the surface wettability as a function of plasma power.

\section{REFERENCES}

[1] P.K. Chu, J.Y. Chen, L.P Wang and N. Huang, "Plasma-surface modification of biomaterials," Mater. Sci. Eng., R, vol. 36, pp. 143-206, March 2002.

[2] A. Eftekhari, L.Li and Y. Yang, "Polyaniline supercapacitors," J. Power Sources, vol. 347, pp. 86-107, April 2017.

[3] P. Sadanand, "Highly sensitive and selective chemiresistor gas/vapor sensors based on polyaniline nanocomposite: A comprehensive review," J. Sci. Advance Materials Devices, vol. 1, pp. 431-453, December 2016.

[4] L. Wei, N.D. Hoa, Y. Cho, D. Kim and J.S. Kim, "Nanofibers of conducting polyaniline for aromatic organic compound sensor," Sensors Actuators, B Chem., vol.143, pp. 132-138, December 2009.

[5] I. Fratoddi, I. Venditti, C. Cametti and M.V. Russo, "Chemiresistive polyaniline-based gas sensors: A mini review," Sensors Actuators, B Chem., vol.220, pp. 534-548, December 2015.

[6] M.M. Ayad, G. El-Hefnawey and N.L. Torad, "A sensor of alcohol vapours based on thin polyaniline base film and quartz crystal microbalance," J. Hazard. Mater., vol.168, pp. 85-88, August 2009.

[7] M.H. Shinen, F.O. Essa and A.S. Naji, "Study the sensitivity of quartz crystal microbalance (QCM) sensor coated with different thickness of polyaniline for determination vapors of ether, chloroform, carbon tetrachloride and ethyl acetate," Chem. Mater. Res., vol. 6, pp. 7-12, 2009.

[8] Z. Ihdene, A. Mekki, B. Mettai, R. Mahmoud, B. Hamada and M.M. Chemimi, "Quartz crystal microbalance VOCs sensor based on dip coated polyaniline emeraldine salt thin films," Sens. Actuators, B., vol. 203, pp. 647-654, November 2014

[9] S. Banerjee, D. Konwar and A. Kumar, "Polyaniline nanofiber reinforced nanocomposite coated quartz crystal microbalance based highly sensitive free radical sensors," Sens. Actuators, B., vol. 171-172, pp. 924-931, August-September 2012.

[10] S. Banerjee, D. Konwar and A. Kumar, "Polyaniline nanofiber reinforced nanocomposite based highly sensitive piezoelectric sensors for selective detection of hydrochloric acid: Analysis of response mechanism," Sens. Actuators, B., vol. 190, pp. 199-207, January 2014.

[11] P. Kunzo, P. Lobotka, M. Micusik and E. Kovacova, "Palladium-free hydrogen sensor based on axygen-plasma-treated polyaniline thin film," Sens. Actuators, B., vol. 171-172, pp. 838-845, August-September 2012.

[12] Masruroh, M.A. Hanif, S.P. Sakti and D.J.D.H. Santjojo, "Plasma power effect on the surface of a quartz crystal during etching using tetrafluoroethane gas," Int. J. Tech., vol. 8, pp. 1525-1532, November 2017. 
[13] S.P. Sakti, R.Y. Aji, L.Amaliya and Masruroh, "Low-cost contact angle measurement system for QCM Sensor," Telkomnika, vol. 15, pp. 560569, June 2017.

[14] N.P.Putri, D.H. Kusumawati, N. Widiyanti and Munasir, "Synthesis of polyaniline/cellulose composite as humidity sensor,” J. Phys. Conf. Ser., vol. 997, 012009, May 2018.

[15] R. Hanna, "Infrared absorption spectrum of silicon dioxide," J. Am. Ceram. Soc., vol. 48, pp. 595-599, November 1965.

[16] M. Blaha, M. Trchova, P. Bober, Z. Moravkova, J. Prokes and J. Stejskal, "Polyaniline: Aniline oxidation with strong and weak oxidants under various acidity," Mater. Chem. Phys., vol. 194, pp. 206-218, March 2017.

[17] George Socrates, Infrared and Raman Characteristic Group Frequencies, 3rd ed., John Wiley \& Sons, 2001
[18] L.A. Can-Herrera, A. Avila-Ortega, S. de la Rosa-Garcia, A.I. Oliva, J.V. Cavich-Rodriguez and J.M. Cervantes-Uc, "Surface modification of electrospun of polycaprolactone nanofibers by air plasma treatment: Effect of plasma power and treatment time," Eur. Polym. J., vol. 84, pp.502-513, September 2016.

[19] A. Vesel, M. Mozetic, A. Hladic, J. Dolenc, J. Zule, S. Milosevic, N. Krstulovic, M. Klanjsek-Gunde and N. Hauptmann, "Modification of ink-jet paper by oxygen-plasma treatment,“ J. Phys. D: Appl. Phys., vol. 40, pp. 3689-3696, June 2007.

[20] Z. Kregar, M. Biscan, S. Milosevic and A. Vesel, "Monitoring oxygen plasma treatment of polypropylene with optical emission spectroscopy," IEEE Trans. Plasma Science, vol. 39, pp.1239-1246, May 2011.

[21] E. Vassallo, A. Cremona, F. Ghezzi and D.Ricci, "Optical emission spectroscopy of an oxygen plasma used for improving PET wettability," Vacuum, vol. 84, pp.902-906, March 2010. 